\title{
3D PRINTING IN THE EDUCATION OF GRAPHIC ENGINEERING AND DESIGN STUDENTS
}

\author{
Bojan Banjanin (D), Magdolna Pál (D), Vladimir Dimovski (D), Savka Adamović (D), Ana Lilić (D) \\ University of Novi Sad, Faculty of Technical Sciences, \\ Department of Graphic Engineering and Design, Novi Sad, Serbia
}

\begin{abstract}
Today, 3D printing is taking its constantly growing part in a lot of different manufacturing industries, educational institutions and a lot of entrepreneurship and home businesses. Besides prototyping and proof of concept, utilization of $3 D$ printing is undoubtedly spreading its roots in manufacturing of production and spare parts but also in aiding research and teaching processes. 3D printing has reinforced the self-employed segment of market called makers but also has influenced forming a significant number of educational online video channels. A lot of crowdfunded web sites promote affordable desktop 3D printers and 3D modellers and designers who design models exclusively for $3 D$ printing, taking its specificity into account. Also, a community of designers, through 3D printing hubs where their work can be purchased, are thriving. There is also a massive trend in developing new materials for 3D printing such as electrically conductive composites, fire-resistant materials and materials with high strength or resilience. In the graphic industry, there is some progress regarding the utilization of $3 D$ printing in the form of tactile maps and picture books, manufacturing customizable packaging, embossing tools, making parts for colour measuring equipment and printing of textiles. However, there is undoubtedly undiscovered usage intended for improvements in this branch of industry. The first part of this research aims to present existing researches and projects regarding the usage of $3 D$ printing in creative and interdisciplinary industries such as graphic industry. The second part of this paper focuses on different initiatives in aiding educational process worldwide, and some of the methodology of implementing 3D printing in education. In the final part of this research, the potential of 3D printing for educational purposes of graphic engineering and design students is discussed. Methodology for getting theoretical and practical knowledge is proposed through a designed catalogue of 3D printing parameters. The purpose of this catalogue is to introduce undergraduate students with one of the most used and affordable 3D printing technique known as Fused Deposition Modelling (FDM) and to provide them with basic knowledge of 3D printing parameters which further on can be expanded and supplemented.
\end{abstract}

Key words: 3D printing, education, graphic industry, printing parameters, FDM

\section{INTRODUCTION}

Additive manufacturing, commonly known as 3D printing, is taking its constantly growing part in a lot of different manufacturing industries, educational institutions and a lot of entrepreneurship and home businesses. Utilization of 3D printing can be seen in different industries, such as engineering, product design, technology, medicine, architecture and entertainment. In all these industries, in order to implement 3D printing in the production process, some form of education and training about basics of 3D printing should be provided to employees or much earlier to students in educational institutions. Therefore, educators need appropriate training, practice, and lastly good teaching plan.

One of the most commonly used and certainly most available and affordable 3D printing technique is Fused Deposition Modelling (FDM). This technique uses printing material in the form of filament (plastic or composite) which is heated through the extruder and melted and deposited through a printing nozzle in successive layers onto the printing platform (also known as build plate). Each layer is cooled down and solidified, which enables the next layer to be deposited. This repetitive process, in the end, forms the desired object. In order to begin printing, first, a 3D model must be acquired. Usually, it is an STL (an acronym for stereolithography), but there can also be used formats such as $3 \mathrm{MF}$ file (.3mf), Wavefront OBJ File (.obj), X3D file (.X3d) etc. Files of 3D models are then prepared in "slicer" software to generate code understandable by 3D printers, called G-code, which contains information about the movement of the print head and all the essential printing parameters needed for the print job.

These different parameters are essential for successful printing, and their combination varies depending on the requirements of the job. Parameters such as printing temperature, layer height, percentage of infill, printing speed etc. are to be taken into consideration when starting a print job. So, it is essential to 
get familiar with them. Every slicer program comes with different capabilities of setting up a print job, and many parameters which can be modified, but some basic knowledge is necessary to begin with printing.

There is an increasing number of educational materials, tutorials, tips and tricks, reviews and projects that are available online. For beginners and, in the case of this research paper, undergraduate students, catalogue of models with the variation of basic printing parameters are printed using FDM 3D printing technique, as an introduction to the understanding of 3D printing process. These printing parameters are essential for designing and modifying different 3D models and prepare them for printing.

\subsection{D printing in creative and interdisciplinary industries}

Production of tactile maps and Braille alphabet has been a popular topic among researchers. In 2009 Voženílek et al. evaluated and developed different aspects of interpretation and perception of geospace by modern tactile maps based on 3D printing. They produced 3D printed tactile maps which can serve for the development of geospace perception and orientation of the blind - both children and adults. The maps will assist in removing the fear of space and recognising unknown places. The new method of 3D printing of tactile maps can be an efficient tool for schools for blind children and many organisations which need to integrate the blind into various activities (employers, shopping centres, transport companies, subjects of emergency management etc.).

Jo et al. (2014) fabricated printed tactile patterns in a size controllable manner with a fused deposition modelling 3D printer. They tested and improved smoothness and interfacial adhesion strength of 3D printed letters and patterns on cellulose paper by using the thermal reflow process as a post-processing step. Thermal reflow was performed to thermally anneal printed patterns on the paper above the PLA

filament temperature $\left(1 \mathrm{~min}\right.$ at $160{ }^{\circ} \mathrm{C}$ on a hot plate in the air). Compared to traditionally punched patterns on paper, the printed dots maintained their original shape without any damage caused to the pattern surfaces before or after the tribology test.

Gual et al. (2014) tested whether the process of memorising a tactile map key or legend can be improved by including three-dimensional (3D) symbols produced utilising 3D printing. They developed the method of using the combination of flat relief symbols (2D elements) with 3D tactile symbols. 3D tactile symbols appear to yield a $48.72 \%$ reduction in the number of errors while identified by the group of 20 participants. This occurs because 3D symbols can be distinguished and memorised better from the 2D features by touch (haptic memory). In 2015 study (Gual et al, 2015), researchers used two maps of the city of Barcelona, one produced on monochrome microencapsulated (swell paper), and the second, that same map, produced using 3D printing. They concluded that the use of tactile 3D symbols improves the mean of time of certain tasks such as the localisation of specific symbols on a map.

In the research paper of Stangl, Kim and Yeh (2014), a 3D printed picture book was designed to aid the educational methodology of children with visual impairments. They focused on 3D printed book because it makes content readily, supports a community that needs specialised, child-specific learning aids, and to use emerging technology as an incentive for parents to become engaged in learning how to design tactile picture books for their children and support emergent literacy skills.

Divine, Thompson and Colson (2016) released a patent on 3D printed packaging, where they describe packaging production line which consists of modules (Scanner module, Modeling module, Print module etc.) and different areas (Scanning area, Printing area, Output area) where products can be scanned, and customised packaging can be printed.

In the fashion industry, 3D printing has an essential role with distinguished fashion designers (Tatiana, 2012; Boorman, 2014; Condon, 2013; Marmey, 2014). Vanderploeg, Lee and Mamp (2016) investigates the potential of five 3D printing techniques, including stereolithography, selective laser sintering, fused deposition modelling, Polyjet, and binder jetting in an application in the fashion industry. They discuss the advantages and disadvantages of each $3 \mathrm{D}$ printing technique and specific printers. They provide a conclusion that design done using 3D CAD software, printers, and materials is a complex process that may require a collaboration of interdisciplinary knowledge and skills.

There are researches done in the field of colour quality evaluation of colour 3D printing. Walters et al. (2009) investigated the capabilities of the powder-binder colour 3D printing system and application of this technology in art and design practice. 3D printed colour test blocks are produced for evaluation of reproduction of primary colours, accuracy and consistency of colour output. GretagMacbeth EyeOne spectrophotometer is used for this research. Results have shown that the reproduction of colours is dependable on the position and orientation of the surface, finishing method and type of printer used. 
They concluded that by developing a practical understanding of materials and process parameters, artists and designers could obtain pleasing creative outcomes.

Yuan et al. (2018) in their paper, discussed standardization efforts of colour quality evaluation of 3D printing techniques. They concluded that it is possible to develop a completed colour quality evaluation standard for colour 3D printing based on approaches in colour 2D printing when colour measurement method and devices are standardized together. Usage of the GretagMacbeth (X-rite) XTH sphere spectrophotometer, the X Rite's TAC7 scanner and MA98 series portable multi-angle spectrophotometer can be used as a 3D object appearance visualization solution.

Two research papers from 2015 (Grasse et al, 2015; Grasse, 2015) describe the creation of portable, FDM 3D printed spectrophotometer and teaching UV - Vis spectroscopy with this device. This allowed to produce an expensive piece of equipment inexpensively and with an open design so that the students can see each relevant part and experiment with the parameters. Another paper from 2016 (Porter et al, 2016) describes user-friendly 3D printed colourimeter models for students to explore instrument design and performance. Authors showed that flexible designs that can be printed quickly and cheaply using consumer-level 3D printers have great potential for students and educators.

Pei, Shen and Watling (2015) investigated adhesion of polymers (acrylonitrile butadiene styrene (ABS), polylactic acid (PLA) and nylon) directly printed onto textiles using entry-level FDM 3D printing technique. They printed decorative and functional parts onto textiles to determine limitations and potential applications of 3D printed textiles.

In the work of Korger et al. (2016), the influence of textile surface properties on the adhesion strength of printed flexible polymers was examined considering mechanical, physical and chemical adhesion mechanisms. They concluded that adhesion strength is influenced by the form-locking connections of the molten polymer with the textile substrate and by the wettability of the textile surface.

Rivera et al. (2017) demonstrated how the malleability, flexibility and aesthetic qualities of textiles can enhance rigid printed objects, and how textiles can be augmented with functional properties enabled by 3D printing. They propose different designs for embedding 3D printed polymers into the textile fabric.

In the work of Spahiu et al. (2017) adhesion of 3D printed polymers onto textile material was investigated. They concluded that parameters such as nozzle temperature and bed temperature have a significant impact on the adhesion force.

One of the 3D printing research fields that are tightly connected to the graphic industry is investigations of presenting 2D images using 3D printers by producing 3D printed lithography pictures. Lithophanes have been used since the 19th century to produce beautiful, but expensive, handcrafted decorations, revealing pictures when lit from behind (Carney, 2012). In the works of Nielsen et al. (2017), Jang and Hong (2017), Weiler et al. (2019), Wang et al. (2020) investigations on converting a 2D image to 3D printed lithophanes and parameters influencing the quality of 3D printed images were described.

\subsection{D printing in education}

In their review paper, Ford and Minshall, 2017 gathered information from other related articles where they found that 3D printing can facilitate learning, develop skills, and increase student engagement. 3D printing can inspire creativity, improve attitudes towards STEM (an acronym for Science, Technology, Engineering, and Mathematics) subjects and careers, while also increasing teachers' interest and engagement. They discuss six main ways how 3D printing is being used in education: "(1) to teach students about 3DP; (2) to teach educators about 3DP; (3) as a support technology during teaching; (4) to produce artefacts that aid learning; (5) to create assistive technologies; and (6) to support outreach activities."

In Table 1, a summary of how 3DP is used in the educational system is presented, according to exhaustive literature review of Ford and Minshall (2017). 
Table 1: Summary of how 3DP is used in educational system is presented (Ford and Minshall, 2017)

\begin{tabular}{|c|c|c|c|c|c|}
\hline & \multicolumn{4}{|c|}{ Where is 3DP being used in the education system? } \\
\hline & & $\underline{\text { Schools }}$ & $\underline{\text { Universities }}$ & $\underline{\text { Libraries }}$ & $\begin{array}{l}\text { Special Education } \\
\text { settings }\end{array}$ \\
\hline \multirow{6}{*}{$\begin{array}{l}\text { How is } \\
\text { 3DP being } \\
\text { used in the } \\
\text { education } \\
\text { system? }\end{array}$} & $\begin{array}{l}\frac{\text { Teaching }}{\text { student about }} \\
\underline{\text { 3DP }}\end{array}$ & $\begin{array}{l}\text { 3DP and 3D } \\
\text { modelling are } \\
\text { introduced to } \\
\text { students during } \\
\text { design and } \\
\text { prototyping } \\
\text { projects in class }\end{array}$ & $\begin{array}{l}\text { The fundamentals } \\
\text { of 3DP and 3D } \\
\text { modelling are } \\
\text { introduced to } \\
\text { engineering and } \\
\text { design students, } \\
\text { who apply their } \\
\text { skills during } \\
\text { in-class projects }\end{array}$ & $\begin{array}{l}\text { Improving } \\
\text { access to 3DP } \\
\text { equipment and } \\
\text { services } \\
\text { enables } \\
\text { self-directed } \\
\text { learning by } \\
\text { students } \\
\text { outside class } \\
\end{array}$ & 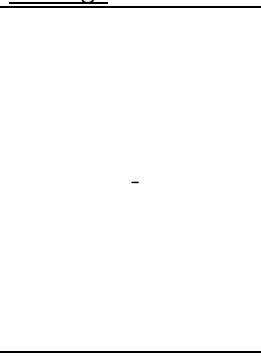 \\
\hline & $\begin{array}{l}\frac{\text { Teaching }}{\text { educators }} \\
\underline{\text { about 3DP }}\end{array}$ & $\begin{array}{l}\text { 3DP and 3D } \\
\text { modelling are } \\
\text { being introduced } \\
\text { to in-service } \\
\text { teachers }\end{array}$ & $\begin{array}{l}\text { 3DP and 3D } \\
\text { modelling are } \\
\text { being introduced } \\
\text { to preservice and } \\
\text { in-service } \\
\text { teachers }\end{array}$ & $\begin{array}{l}\text { Training } \\
\text { Librarians } \\
\text { enables them } \\
\text { to operate and } \\
\text { maintain 3DP } \\
\text { equipment, and } \\
\text { troubleshoot } \\
\text { 3D modelling } \\
\text { problems }\end{array}$ & - \\
\hline & $\frac{\frac{\text { Using 3DP }}{\text { during }}}{\text { teaching }}$ & $\begin{array}{l}\text { Using 3DP during } \\
\text { class projects to } \\
\text { improve student } \\
\text { engagement and } \\
\text { understanding of } \\
\text { STEM subjects }\end{array}$ & $\begin{array}{l}\text { Using 3DP during } \\
\text { class projects to } \\
\text { improve student } \\
\text { engagement and } \\
\text { understanding of } \\
\text { STEM subjects }\end{array}$ & - & $\begin{array}{l}\text { Using 3DP to create } \\
\text { custom adaptive } \\
\text { devices and } \\
\text { educational aids }\end{array}$ \\
\hline & $\begin{array}{l}\text { Using 3DP to } \\
\text { produce } \\
\text { artefacts that } \\
\text { aid learning }\end{array}$ & - & $\begin{array}{l}\text { 3DP models } \\
\text { enable hands-on } \\
\text { learning in } \\
\text { lectures and lab } \\
\text { sessions, } \\
\text { particularly in } \\
\text { anatomy and } \\
\text { chemistry } \\
\text { teaching }\end{array}$ & - & - \\
\hline & $\begin{array}{l}\text { Using 3DP to } \\
\text { create } \\
\text { assistive } \\
\underline{\text { technologies }}\end{array}$ & - & - & - & $\begin{array}{l}\text { Expands the range } \\
\text { of student learning } \\
\text { opportunities, } \\
\text { particularly among } \\
\text { those with visual } \\
\text { impairments }\end{array}$ \\
\hline & $\begin{array}{l}\text { Using 3DP to } \\
\frac{\text { support }}{\text { outreach }} \\
\underline{\text { activities }}\end{array}$ & $\begin{array}{l}\text { Using 3DP during } \\
\text { university outreach } \\
\text { programs improves } \\
\text { student } \\
\text { engagement with } \\
\text { STEM subjects }\end{array}$ & - & - & - \\
\hline
\end{tabular}

Ford and Minshall (2017) concluded that there is a need for additional teaching support materials for simplifying the process of integration of 3D printing into teaching, both for understanding and practice of 3D printing process and as an aiding tool in student engagement and subject knowledge acquisition.

Kostakis et al. (2014) researched to what extent the technological capabilities of open-source 3D printing could serve as a means of learning and communication. Thirty-three students from two high schools in Greece collaboratively worked on design and production of creative artefacts using an open-source 3D printer and 3D design platform. They sent those products to blind children initiating a novel way of communication and collaboration amongst blind and non-blind students. They had positive feedback and agreed that 3D printing and design could "electrify" various literacies and creative capacities of children. Their students, who were, to some extent, indifferent about their project class, when given proper 
stimulation and tools can choose what to learn themselves through exploration. They had an opportunity to truly engage in the whole process by materializing a product from an idea, and they acquired knowledge instead of dry information out of textbooks.

In the work of Menano et al. (2019) authors investigated the integration of 3D printing in art education. After reviewing papers written about the researched topic, authors stated that using 3D printing promotes student creativity and motivation, and helps them in understanding the relationship between 2D and 3D space. It aids students in the implementation of a design process. However, there is a lack of support and training for teachers as well as limited access to equipment. They concluded that it is essential for the educational system to adapt, transform and modernize to prepare future generations better and that educators must collaborate using art and technology to develop common interests and projects. 3D printing can also be beneficial to teachers and educators and not solely to students. In the research paper written by Novak and Wisdom (2020), the authors investigated the influence of using 3D printing in science for elementary teachers. The goal of this study was to positively impact teachers' attitudes toward teaching science while enhancing their understanding of how engineers approach the design process. They recorded that design thinking, teaching efficiency and science interest improved, and anxiety about teaching science dropped.

Verner and Merksamer (2015) investigates changes in the Techion technology/mechanics teacher education courses and impact these changes brought in enhancing students' knowledge and skills in teaching digital design and manufacturing. They equipped their department laboratory of technology with CAD software tools and a 3D printer, and they upgraded the course to meet the conceive-designimplement-operate (CDIO) approach. They concluded that learning activities with CAD software and 3D printer significantly enhance students' practice of visual-spatial skills.

There is a particular interest in incorporating 3D printing in the field of graphic design. Sampaio et al. (2013) investigate the implementation of 3D printing technology in a graphic design course. They identified that there is an increasing interest of students for the issues of dealing with representation and the conversion of the three-dimensional structures in tangible interfaces, such as the design of packaging, signage, game design, animation, children books and toys, among many others that are related to graphic design. Each of the five graduating students has a task to research one possibility of use for FDM 3D printing technique. Guidelines for the projects such as an emphasis on practical learning and its systematization, encouraging creative experimentation, innovation and entrepreneurship and multi and interdisciplinary approach were established. For sub-themes, they researched the creation of anthropometric dummies, systems of characters and scenarios for stop motion animation, perception of tactile textures for the blind, new concepts for packaging and redesign of the 3D printer. They also participated in the contest with the design solution of product which aid children from 3 to 5 years with partial or total amputation of the upper limb in conducting everyday tasks. They found an increasing trend in students' learning process of three-dimensional representation in the virtual world but also as 3D printed objects. Also, the learning of the printing parameters that influence properties of 3D printed products such as wall thickness, or minimum resolutions of the models or corrects preparation of STL files were improved.

\section{METHODS}

According to the research of Ford and Minshall (2017), the starting point in teaching 3D printing to university students is teaching the fundamentals of 3D printing and 3D modelling. At the Department of Graphic Engineering and Design students are introduced to fundamentals of 3D modelling in the second year of undergraduate academic studies when they learn to work in 3D CAD software, by getting familiar with virtual 3D space and basics of designing graphic products. Further on, they continue to foster their 3D modelling skills in the third year in the two subjects: Fundamentals of spatial design and Industrial design. In the third year of undergraduate academic studies, they begin to learn about the fundamentals of 3D printing within the Industrial design course. A detailed explanation of 3D printing techniques and their specificity is covered at master academic studies in the 3D printing course.

In the work of Erickson (2017) 3D modelling poster called "Essentials of 3D Printing" was designed. Author of this poster covers some of the essential 3D printing parameters by designing 3D models which can be downloaded, printed and then fixed on the cardboard poster. Inspired by this initiative to educate students about fundamentals of 3D printing in a haptic manner, we decided to broaden this set of parameters by introducing new ones which are the most common but also some of the advanced ones which are related to the type of slicing software. These broaden set of 3D printed artefacts can be applied 
to the poster, similar to one that Erickson proposed or be kept in storage boxes or registrar to be viewed by students alongside teaching sessions during their classes. In Table 2, printing parameters for artefacts used in this study are presented. These parameters are essential in any slicer software, but names from Table 2 are from Ultimaker Cura slicer software (version 4.6.2) used in this research.

Table 2: Chosen 3D printing parameters used in this study

\begin{tabular}{|c|c|}
\hline Parameter/mods/artifacts & Parameter value \\
\hline Non-printed filament & $1.75 \mathrm{~mm}$ thickness \\
\hline Extruded filament & $0.4 \mathrm{~mm}$ nozzle diameter \\
\hline Line width (deposited on the printing bed) & $0.4 \mathrm{~mm}$ \\
\hline Build plate adhesion (Skirt - line count) & 3 \\
\hline Build plate adhesion (Brim - width) & $8 \mathrm{~mm}$ \\
\hline Build plate adhesion (Raft - extra margin) & $15 \mathrm{~mm}$ \\
\hline Wall line count (wall thickness) & $1 ; 3 ; 6(0.4 \mathrm{~mm} ; 1.2 \mathrm{~mm} ; 2.4 \mathrm{~mm})$ \\
\hline Top/bottom thickness & $\begin{array}{l}\text { without top layers; w/o bottom; w/o top\&bottom; } \\
2 \text { layers }\end{array}$ \\
\hline Top/bottom pattern & Lines; Concentric; Zig Zag \\
\hline Layer height & $0.1 \mathrm{~mm} ; 0.2 \mathrm{~mm} ; 0.3 \mathrm{~mm} ; 0.4 \mathrm{~mm}$ \\
\hline Infill density & $0 \% ; 20 \% ; 40 \% ; 60 \% ; 80 \% ; 100 \%$ \\
\hline Infill pattern & $\begin{array}{l}\text { Lines; Triangles; Grid; Tri-Hexagon; Octet; Cross; Cross } \\
\text { 3D, Gyroid, Concentric }\end{array}$ \\
\hline Overhang angles & $\begin{array}{l}15^{\circ} ; 20^{\circ} ; 25^{\circ} ; 30^{\circ} ; 35^{\circ} ; 40^{\circ} ; 45^{\circ} ; \\
50^{\circ} ; 55^{\circ} ; 60^{\circ} ; 65^{\circ} ; 70^{\circ} ; 75^{\circ} ; 80^{\circ} \\
\end{array}$ \\
\hline Support structures & with/without support structures \\
\hline Support pattern & Zig Zag; Triangles; Gyroid \\
\hline Printing temperature test & $\begin{array}{c}180{ }^{\circ} \mathrm{C} ; 185^{\circ} \mathrm{C} ; 190{ }^{\circ} \mathrm{C} ; 195^{\circ} \mathrm{C} ; \\
200{ }^{\circ} \mathrm{C} ; 205^{\circ} \mathrm{C} ; 210^{\circ} \mathrm{C} ; 215^{\circ} \mathrm{C} ; 220^{\circ} \mathrm{C}\end{array}$ \\
\hline Tree support structures (Experimental mode) & - \\
\hline Spiralize outer contour (Vase mode) & - \\
\hline Mold mode & - \\
\hline Failed prints (showcase) & - \\
\hline
\end{tabular}

\subsection{Materials and printer settings}

3D printing filament made from Polylactic Acid (PLA) was used in this research. The diameter of the filament used was $1.75 \mathrm{~mm}$. Artefacts were printed at room temperature of $23 \pm 2^{\circ} \mathrm{C}$ using Creality CR10S Pro FDM 3D printer. The temperature of the printing bed was set to $50{ }^{\circ} \mathrm{C}$, and the temperature of the printing nozzle was $200{ }^{\circ} \mathrm{C}$ (except for the temperature test). Printing speed was set to $50 \mathrm{~mm} / \mathrm{s}$ with enabled retraction (Retraction distance: $6 \mathrm{~mm}$; Retraction speed: $45 \mathrm{~mm} / \mathrm{s}$ ).

After setting the list of desired 3D printing parameters, 3D models are created using Autodesk Fusion 360 CAD software, which is simplified version of Autodesk Inventor, and which is broadly used in makers' circles due to its' simplicity and fast learning curve. Each model has created bearing in mind which 3D printing parameter it needs to emphasize. Some of the models are downloaded from Thingiverse web site to show particular slicing mode (e.g. Vase (JJ76, 2018), Mold (Erickson (2017)), stringing effect using different temperatures or overhang angles (Stainhausler, 2017).

\section{RESULTS AND DISCUSSION}

Figures 1-8 showcase 3D printed artefacts using different printing parameters, mods, or some specific attribute. These are only images with some of the parameters visible. However, more detailed experience using a combination of visual and haptic senses can convey texture, structure, size and all the other attributes necessary for the more in-depth understanding of fundamentals of 3D printing.

Figure 1 represents 3D printing material and different ways parts can be adhered to build plate. 
a)

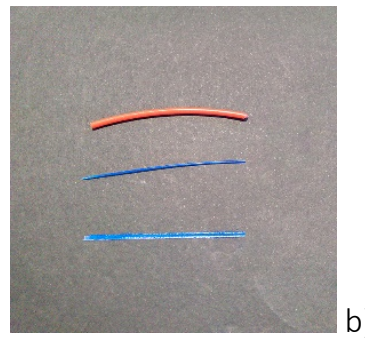

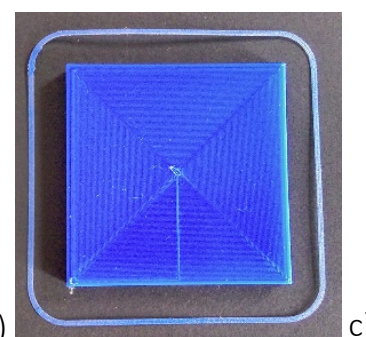

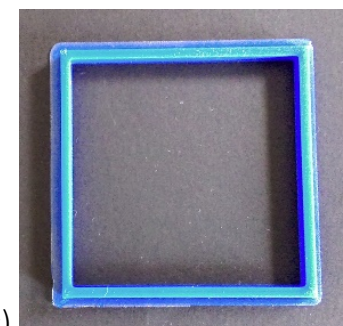

c)

d)

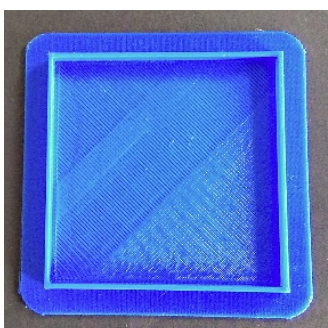

Figure 1: a) unextruded (1.75 mm), extruded $(0.4 \mathrm{~mm})$ and printing filament adhered on build plate (Line width); $b$ ) part with a skirt; c) with brim; and d) with raft

The skirt is usually used and recommended to be able to extrude some of the material on the build plate before printing a model and to ensure good adhesion of the first deposited layer. Brims are usually used when printing a large or long and thin part to increase the contact area with build plate and in that way to prevent printed parts from detaching due to deformation caused by cooling of deposited layers. Rafts are not recommended to be used often because of prolonging the printing time and using extra material but can be useful to compensate inconsistent build plate levelling. Different settings for the number of part contours (wall line count) are presented in Figure 2.
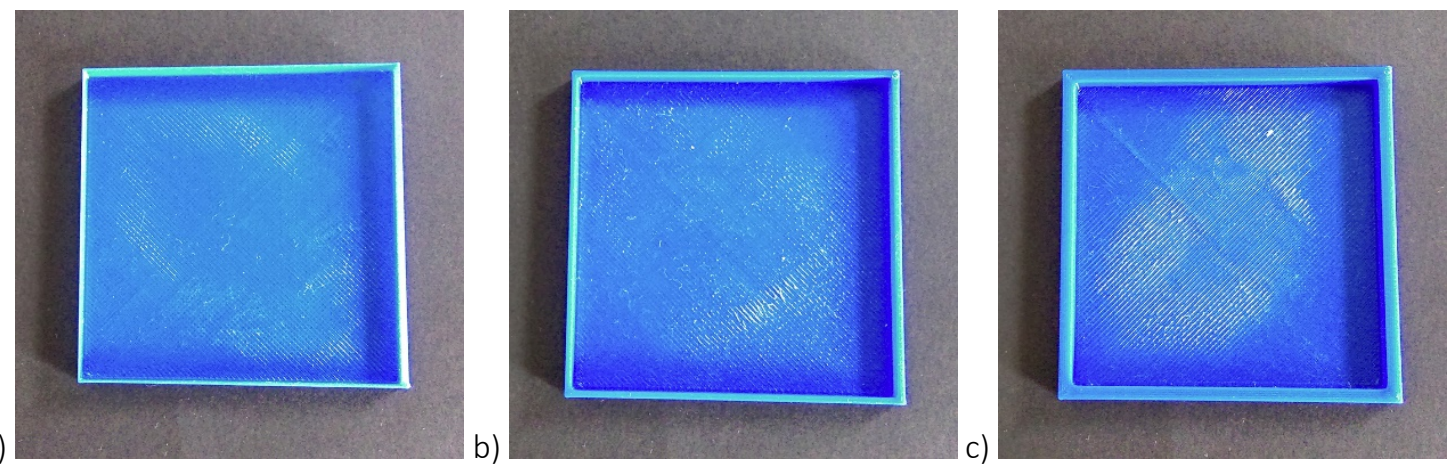

Figure 2: Wall line count. a) one, b) three and c) six walls. Printed with bottom layers and without top layers

Parts with higher wall count are sturdier then parts with less wall count, but printing time can be significantly prolonged. So it is a matter of optimization depending on the part structure and requirements for its proper use. These parts are printed without top layers and infill to emphasize the thickness of walls better.

On Figure 3, different patterns of top printed layers are presented. Each slicing software has its patterns for the top and bottom layers, and in this paper, only some of them available in Ultimaker Cura slicing software are presented. On some parts where these parameters can influence the aesthetic look of the finished product, usage of these patterns can be useful.

a)

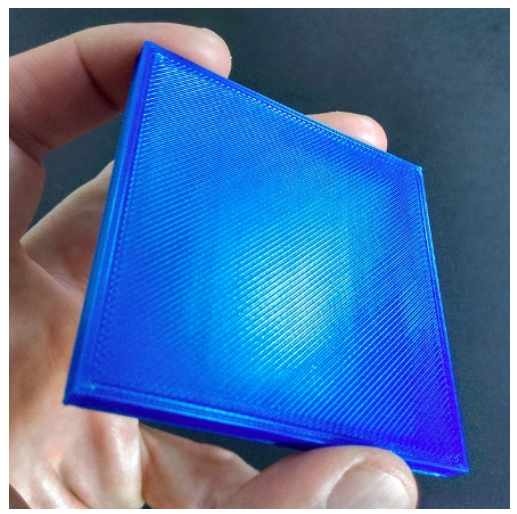

b)

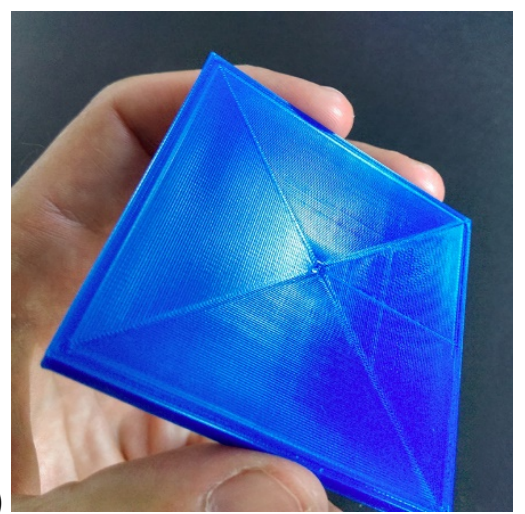

Figure 3: Top layers printed with different patterns. a) Lines and b) Concentric pattern 
Figure 4 presents a different setting for the layer height parameter. A suitable 3D model with smooth curves was created to emphasize changes made by modifying this parameter.
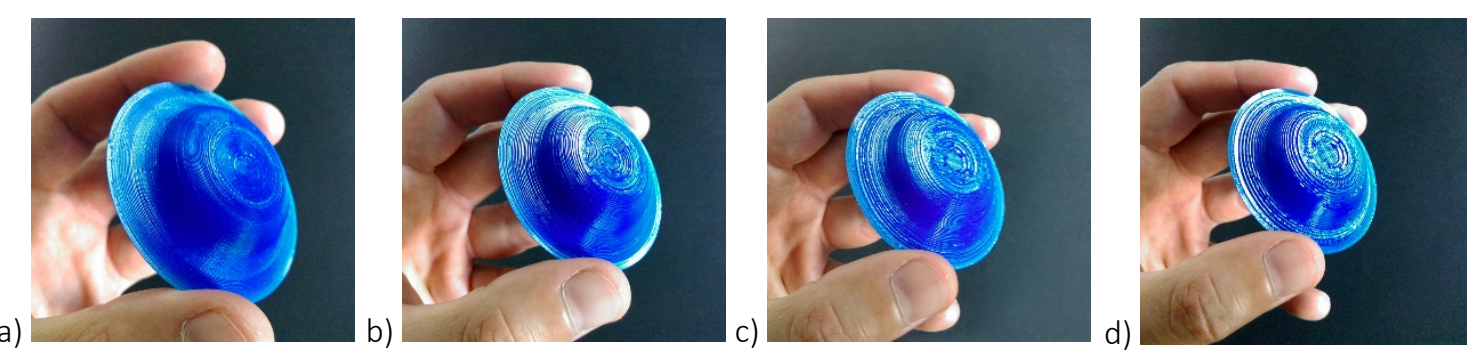

Figure 4: Models with varied layer height. a) $0.1 \mathrm{~mm}$, b) $0.2 \mathrm{~mm}$, c) $0.3 \mathrm{~mm}$, and d) $0.4 \mathrm{~mm}$

Layer height in great extent influence visual look and feel of side surfaces (surfaces along the z-axis) which can be seen from Figure 4. Increasing the layer height, the so-called "staircase effect" is more noticeable. One of the most used and changed parameters, after layer height, is the percentage of infill. In Figure 5, different percentages of infill are presented.

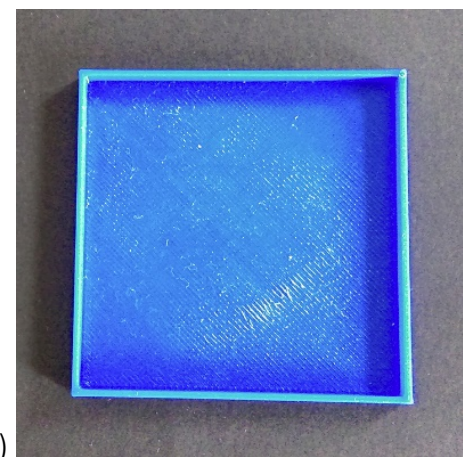

а)

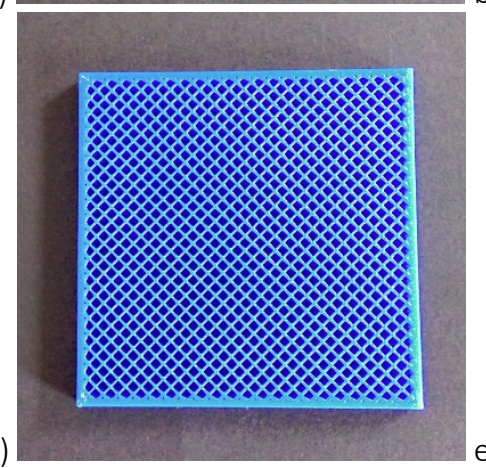

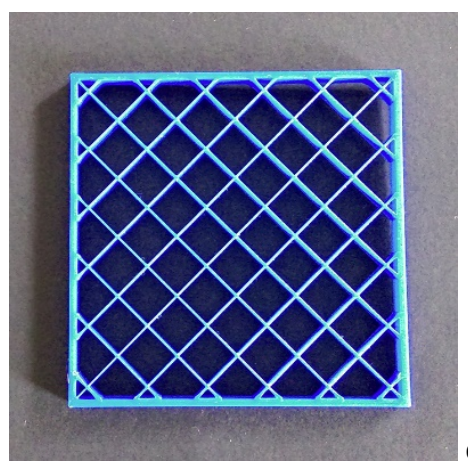

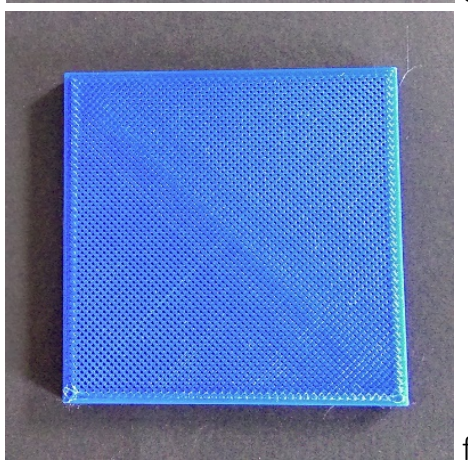

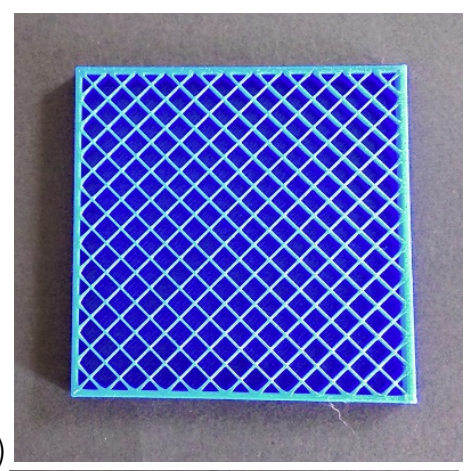

c)

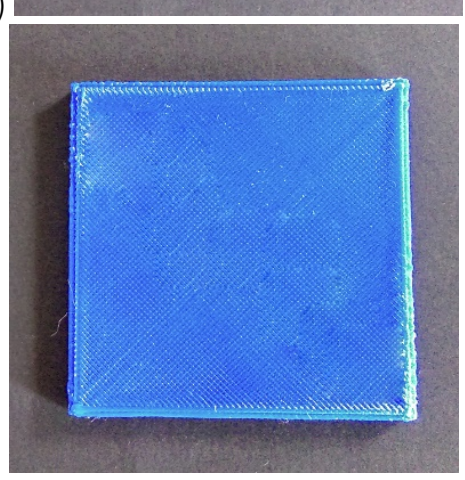

Figure 5: Models with varied percentage of infill. a) $0 \%$, b) $20 \%$, c) $40 \%$, d) $60 \%$, e) $80 \%$, and f) $100 \%$ infill

Denser the infill structure is, more printing time is required. Optimized usage of infill percentage can lead to the increased strength of the printed part, which does not mean that $100 \%$ infill is the most optimal choice. $80 \%$ infill can, in some cases, lead to similar mechanical properties of the part but with faster print time.

One of the fundamental parameters concerning infill is infill pattern (Figure 6). This parameter varies between different slicing software, and its careful consideration can improve the mechanical properties of the printed parts or lead to reduced print time. 
а)

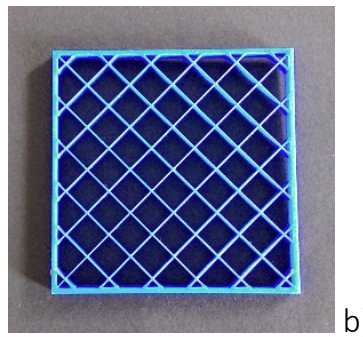

。

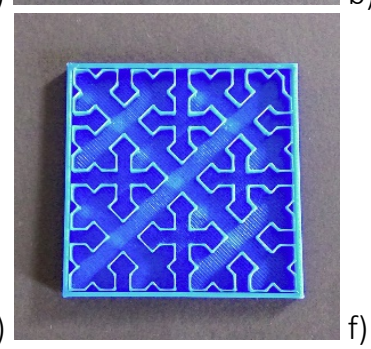

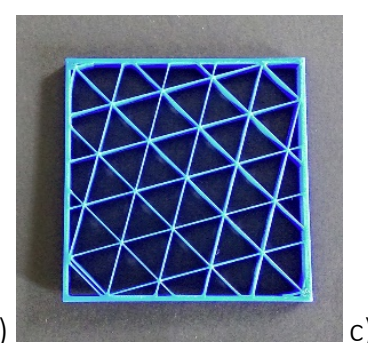

)

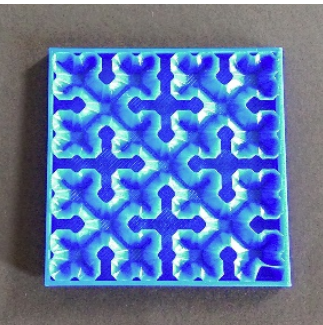

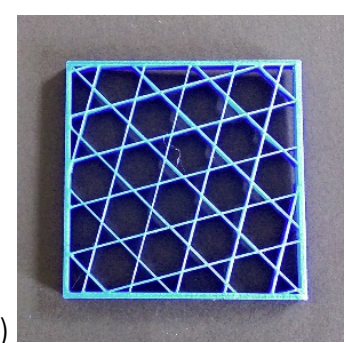

,

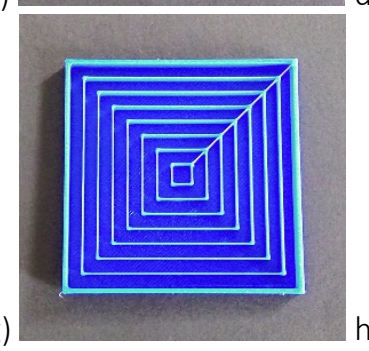

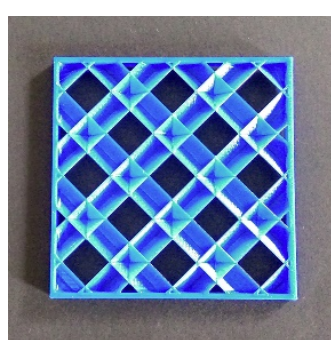

d)

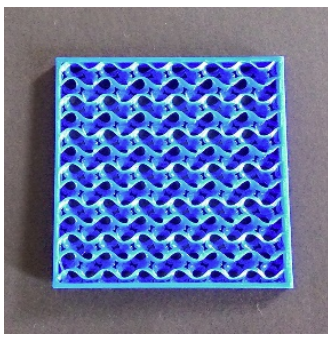

Figure 6: Models with varied infill pattern. a) grid, b) triangles, c) Octet, d) Tri-Hexagon, e) Cross, f) Cross 3D, g) Concentric, and h) Gyroid infill pattern

When printing parts with overhangs it is crucial to know capabilities of the printer, material properties, but also it is essential to generate support structures for the overhang angles which would collapse without them during the printing. These structures support these parts of models during the printing and can be removed after the printing process is finished. On Figure 7 a), b) and c) support structures with different patterns are presented. Figure 7d presents Ultimaker Cura experimental mode called Tree supports.

a)
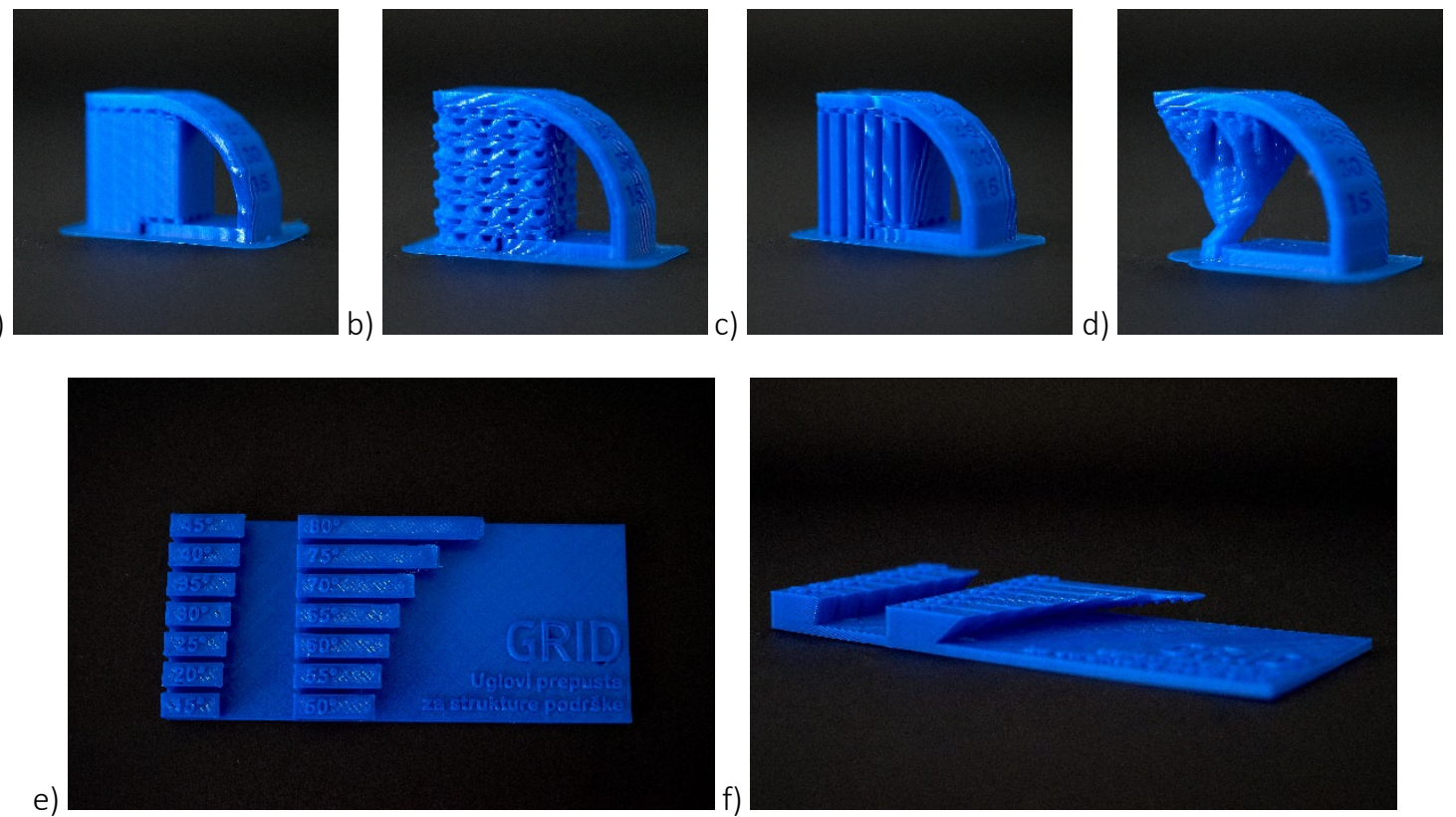

Figure 7: Models with different support pattern. a) Zig Zag, b) Gyroid, c) Triangles, and d) tree support structure.

e) if) represent model with different overhang values and no support structures

It is usually good practice to print test models to get familiar with the capabilities of the printer and material properties to see which overhang angles can be printed without supports and which requires them (Figure 7e). Then, it can be set in the slicing software when to generate support structures or in which way to model parts, so they do not require support structures. Figure 8 represents different artefacts used for education and learning different capabilities of the printer or the slicing software such as the influence of different printing temperatures (Figure 8a), vase mode (Figure 8b), mold mode (Figure 
$8 \mathrm{c})$, or to showcase some of the failed prints and open discussion about what caused that type of error (Figure 8d).

a)

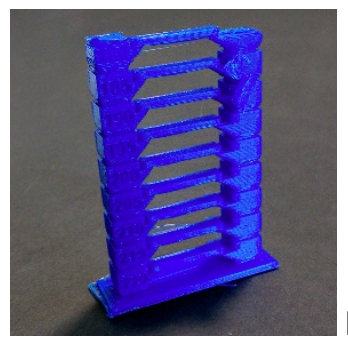

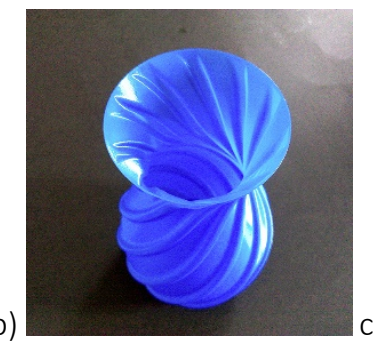

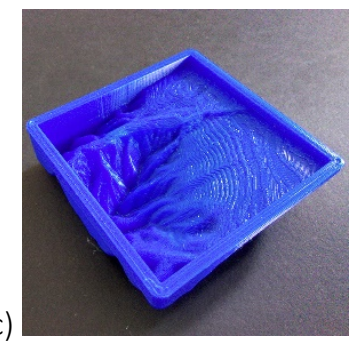

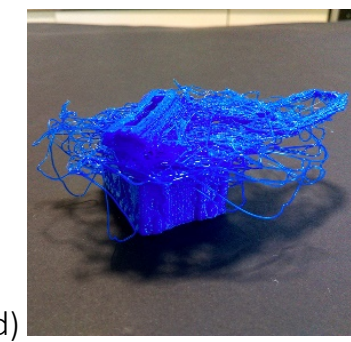

Figure 8: Different artifacts. a) "temperature tower" for testing influence of different nozzle temperatures on stringing and bridges, b) part printed with only one wall - Vase mode, c) 3D printed mold, d) example of failed print

Print temperature towers (Figure 8a) are usually used to test different printing temperatures with selected material to be able to see the optimum temperature for the printing of bridges (short unsupported beams) or to see which temperature leads to a minimum amount of stringing (oozing of extruded filament during travelling of the print nozzle). Spiralize outer contour (better known as Vase mode) is generally used for printing large volume parts which are hollow such as vases to minimize print time. These objects are printed with only one wall and are not so sturdy (Figure 8b). Mold mode is presented here to show some built-in capabilities of the slicing software (Figure $8 \mathrm{c}$ ). This mode allows injecting silicone or other casting material into the mold in order to get the final part. This can be useful for serialized production of the same part, but this option is still in developing, and there are different ways of creating molds for these kinds of jobs.

Printed artefacts are created in such manner that they can be fixed to some flat and hard surface (cardboard, plywood, plastic sheet) or can be gathered in the form of the registrar or placed in separated boxes for showcase purposes.

\section{CONCLUSIONS}

In this research paper, different ways of using 3D printing in interdisciplinary industries such as graphic engineering and design are discussed, and some practices of integrating 3D printing in education process are reviewed. There are a variety of research articles about 3D printed tactile elements such as Braille alphabet or different kind of maps for visually impaired persons, which introduce this prosperous technology with the aim of aiding and/or improving conventional methods of production. Some projects involve the production of an entire picture book using 3D printing to aid visually impaired children in the learning process.

Investigations are done in the field of joining different substrates, such as paper and textile with 3D printed polymers to test adhesive properties and rubbing or washing resistance of such elements. Experiments are done in the construction of relatively cheap colour measurement devices using 3D printing and using these devices in student education, which opens an opportunity for every student to participate in modelling, assembling and using these devices and having a better understanding how these devices work.

Interesting topics in the field of generating and printing 3D lithophane images from 2D images using a 3D printing technique are also investigated in the research community. Specific tools for automating this conversion process are available online for the broader public to experiment and make their lithophanes. In the education process, throughout the myriad of research papers, 3D printing is reported to have a positive impact on the learning and teaching process, involving both students and teachers more deeply in curriculum topic. More creativity, understanding and enthusiasm are triggered by involving 3D printing in the classes. It is reported that design thinking skills, teaching and learning efficiency is increased and anxiety on teaching certain subjects decreased.

Implementing of 3D printing in the curriculum for undergraduate students of Department of graphic engineering and design, after reviewing scientific literature, can definitively have a tremendous positive impact on students' and teachers' engagement improving both the learning and the teaching experience. The first step in this implementation process is getting familiar with the fundamentals of 3D printing process parameters and then finding a novel and creative ways of using this technology as an aiding tool 
in the graphic industry. The haptic experience involved with 3D printing, based on the reviewed literature, generally helps in better understanding of observed parts and in case of 3D printed artefacts done in this research paper it definitively can improve students' learning process.

Further research can be done by interviewing students about 3D printing fundamentals using physically 3D printed parts and comparing those results with a group of students who only used visual apparatus throughout the learning process. Also, the collection of printing parameters presented in this paper can be further on expanded in order to cover some of the advanced printing parameters and problems which can be solved by thoroughly understanding of these parameters.

\section{ACKNOWLEDGMENTS}

This research (paper) has been supported by the Ministry of Education, Science and Technological Development through the project no. 451-03-68/2020-14/200156: "Innovative scientific and artistic research from the FTS (activity) domain".

\section{REFERENCES}

[1] Boorman E.:"3D Printing Spotted at NY Fashion Week in Katie Gallagher's Spring/Summer 2015 Collection", URL http://www.materialise.com/blog/3d-printingspotted-ny-fashion-weekkatiegallaghers-springsummer-2015-collection/ (last request: 2020-08-15).

[2] Carney, M.: "Lithophanes... not a dead art form", Ceramics Art and Perception 87, 24-27, 2012.

[3] Condon C.: "How Fashion Designers Incorporate 3D Printing in their Work", URL: http://www.beyonddesignchicago.com/how-fashiondesigners-incorporate-3d-printing-in-theirwork/ (last request: 2020-08-15)

[4] De Sampaio, C. P., Spinosa, R. D. O., Tsukahara, D. Y., da Silva, J. C., Borghi, S. L. S., Rostirolla, F., Vicentin, J.: "3D printing in graphic design education: Educational experiences using Fused Deposition Modeling (FDM) in a Brazilian university", Proceedings of 6th International Conference Advanced Research Virtual Rapid Prototyping 2013, (VRAP 2013: Leiria, Portugal, 2013), pages 25-30.

[5] Divine, D. A., Thompson, D. S., Colson, S. C.: US 9,248,611, “3-D printed packaging", United States Patent, 2016.

[6] Erickson, R.: "3D modeling poster", URL: https://www.thingiverse.com/thing:2142384 (last request: 2020-08-21).

[7] Ford, S., Minshall, T.: "3D printing in teaching and education: A review of where and how it is used", Additive Manufacturing 25, 131-150, 2017. doi:10.1016/j.addma.2018.10.028.

[8] Grasse, E. K., Torcasio, M. H., Smith, A. W.: "Teaching UV-Vis spectroscopy with a 3D-printable smartphone spectrophotometer", Journal of Chemical Education 93 (1), 146-151, 2016. doi: 10.1021/acs.jchemed.5b00654.

[9] Grasse, E. K.: "Creation of a portable, 3D-printable, iPhone-compatible spectrophotometer", HonorsResearch Projects, URL: https://core.ac.uk/download/pdf/232670827.pdf (last request: 2020-08-21).

[10] Gual, J., Puyuelo, M., \& Lloveras, J.: "Three-dimensional tactile symbols produced by 3D Printing: Improving the process of memorizing a tactile map key", British Journal of Visual Impairment 32 (3), 263-278, 2014. doi:10.1177/0264619614540291.

[11] Gual-Ortí, J., Puyuelo-Cazorla, M., Lloveras-Macia, J.: "Improving tactile map usability through 3D printing techniques: an experiment with new tactile symbols", The Cartographic Journal 52 (1), 5157, 2015. doi: 10.1179/1743277413Y.0000000046.

[12] Jang, S. H., Hong, J. M.: "An Adaptive Extrusion Control Technique for Faster FDM 3D Printing of Lithophanes", Korean Journal of Computational Design and Engineering 22 (2), 190-201, 2017. doi:10.7315/CDE.2017.190.

[13] JJ76, "Spiral vase", URL: https://www.thingiverse.com/thing:2795194 (last request: 2020-08-15).

[14] Jo, W., Lee, J. S., Lee, H. J., Moon, M. W.: "3D printed tactile pattern formation on paper with thermal reflow method", RSC Advances, 4 (60), 31764-31770, 2014. doi: 10.1039/C4RA02822H.

[15] Korger, M., Bergschneider, J., Lutz, M., Mahltig, B., Finsterbusch, K., Rabe, M.: “Possible applications of 3D printing technology on textile substrates", IOP Conference Series: Materials Science and Engineering (IOP Publishing, Moenchengladbach, 2016.), pages 1-5. 
[16] Kostakis, V., Niaros, V., Giotitsas, C.: "Open source 3D printing as a means of learning: An educational experiment in two high schools in Greece", Telematics and informatics 32 (1), 118-128, 2015. doi:10.1016/j.tele.2014.05.001.

[17] Marmey E.: "Buy Lingerie Design Online And 3D-Print it at Home", URL: http://fashionlab.3ds.com/buy-lingerie-design-online-and-3-print-it-at-home/ (last request: 2020-08-15).

[18] Menano, L., Fidalgo, P., Santos, I. M., Thormann, J.: "Integration of 3D Printing in Art Education: A Multidisciplinary Approach", Computers in the Schools 36 (3), 222-236, 2019. doi: 10.1080/07380569.2019.1643442.

[19] Nielsen, J. B., Eiríksson, E. R., Lyngby, R., Wilm, J., Jensen, J. N., Aanæs, H., Pedersen, D. B.: “PicPrint: Embedding pictures in additive manufacturing", Euspen and ASPE Special Interest Group Meeting: Additive Manufacturing 2017, (Leuven, Belgium, 2017)

[20] Novak, E., Wisdom, S.: "Using 3D printing in science for elementary teachers", Active Learning in College Science (Springer, Cham, 2020.), pages 729-739.

[21] Pei, E., Shen, J., Watling, J.: "Direct 3D printing of polymers onto textiles: experimental studies and applications", Rapid Prototyping Journal 21 (5), 556-571, 2015. doi: 10.1108/RPJ-09-2014-0126.

[22] Rivera, M. L., Moukperian, M., Ashbrook, D., Mankoff, J., Hudson, S. E.: "Stretching the bounds of 3D printing with embedded textiles", Proceedings of the $\mathrm{CHI}$ Conference on Human Factors in Computing Systems 2017, (CHI '17: Denver, Colorado, 2017), pages 497-508.

[23] Spahiu, T., Grimmelsmann, N., Ehrmann, A., Piperi, E., Shehi, E.: (2017) “Effect of 3D printing on textile fabric", Proceedings of the $1^{\text {st }}$ International Conference Engineering and Entrepreneurship (ICEE-2017: Welhai, China, 2017), pages 1-7.

[24] Stangl, A., Kim, J., Yeh, T.: "3D printed tactile picture books for children with visual impairments: a design probe", Proceedings of the 2014 conference on Interaction design and children (IDC '14: Aarhus, Denmark, 2014), pages 321-324.

[25] Stainhausler: "Better temperature tower 240-180", URL: https://www.thingiverse.com/thing:2625999 (last request: 2020-08-15).

[26] Tatiana: "Iris Van Herpen: taking her dresses a level higher", URL: https://i.materialise.com/blog/irisvan-herpen-taking-her-dresses-alevel-higher (last request: 2020-08-15).

[27] Vanderploeg, A., Lee, S. E., Mamp, M.: "The application of 3D printing technology in the fashion industry", International Journal of Fashion Design, Technology and Education 10 (2), 170-179, 2017. doi:10.1080/17543266.2016.1223355.

[28] Verner, I., Merksamer, A.: "Digital design and 3D printing in technology teacher education", Procedia Cirp 36, 182-186, 2015. doi: 10.1016/j.procir.2015.08.041.

[29] Voženílek, V., Kozáková, M., Štávová, Z., Ludíková, L., Růžičková, V., Finková, D.: “3D Printing technology in tactile maps compiling", Proceedings of 24th International Cartographic Conference, International Cartographic Association, (ICC2009: Santiago, Chile, 2009), pages 15-21.

[30] Walters, P., Huson, D., Parraman, C., Stanić, M.: “3D printing in colour: Technical evaluation and creative applications", Impact 6 international printmaking conference 2009, (IMPACT 6: Bristol, United Kingdom, 2009).

[31] Weiler, J.: "Beyond Plastic Filament: An Exploration of 3D Printing as a Part of Creative Practices", PhD thesis, Arizona State University, 2020.

[32] Yuan, J., Zhu, M., Xu, B., Chen, G.: "Review on processes and color quality evaluation of color 3D printing”, Rapid Prototyping Journal 24 (2), 409-415, 2018. doi: 10.1108/RPJ-11-2016-0182.

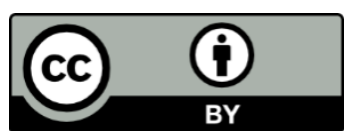

(C) 2020 Authors. Published by the University of Novi Sad, Faculty of Technical Sciences, Department of Graphic Engineering and Design. This article is an open access article distributed under the terms and conditions of the Creative Commons Attribution license 3.0 Serbia (http://creativecommons.org/licenses/by/3.0/rs/). 